\title{
STUDI ANALISA PERENCANAAN PERKERASAN LENTUR DAN RENCANA ANGGARAN BIAYA (PADA PROYEK JALAN RUAS JALAN TAMBELANGAN - DURJAN KABUPATEN SAMPANG)
}

\author{
Mishbahul Aziz *1, Sigit Winarto ${ }^{2}$, Yosef Cahyo SP ${ }^{3}$, Agata Iwan Candra ${ }^{4}$. \\ ${ }^{1,2,3}$ Fakultas Teknik, Universitas Kadiri. \\ e-mail:*1'misbahulaziz7@gmail.com,2sigit.winarto@unik-kediri.ac.id, \\ 3yosef.cs@unik-kediri.ac.id, ${ }^{4}$ iwan_candra@unik-kediri.ac.id
}

\begin{abstract}
There was a build-up of lumps of sand on the road, precisely Tambelang-Durjan. This build-up of sand chunks occurs because many of the piled sand hauling trucks that pass on the road is obstructed because the road section has been damaged (potholes) and is unfit for passage, resulting in obstruction of traffic flow. In addition, the width of the section is not in accordance with the technical requirements of the 2011 Government Regulation. Therefore, it requires a flexible pavement re-planning and a Cost Budget Plan for land transportation lines, so that motorist access is comfortable. Planning flexible pavement using Laston with a planning age of 10 years obtained flexible pavement thickness, namely $4 \mathrm{~cm}$ thick $A C-W C, 6 \mathrm{~cm}$ thick $A C-B C$, and $40 \mathrm{~cm}$ of Upper Foundation Layers (LPA) with the estimated size of the Budget Plan The cost of the flexible pavement construction of Tambelang-Durjan of Sampang Regency with a length of 1,145 km in the amount of $R p 5,744,585,463.00$.
\end{abstract}

Keywords: $\quad$ Flexible Pavement, Widening, Cost, Transportation

\begin{abstract}
Abstrak
Terjadi penumbukan bongkahan pasir urug tepatnya di ruas jalan Tambelangan-Durjan. Penumpukan bongkahan pasir ini terjadi karena banyak truk pengangkut bongkahan pasir urug tersebut yang melintas pada jalan itu terhambat karena ruas jalan mengalami kerusakan (berlubang) dan tidak layak dilalui, sehingga yang mengakibatkan terhambatnya arus lalu lintas. Selain itu lebar ruas tidak sesuai dengan persyaratan teknis Peraturan Pemerintah tahun 2011. Oleh karena itu, memerlukan perencanaan ulang perkerasan lentur dan Rencana Anggaran Biaya untuk jalur transportasi darat supaya akses pengendara nyaman. Perencanaan perkerasan lentur menggunakan Laston dengan umur rencana 10 tahun didapatkan tebal perkerasan lentur yaitu AC-WC setebal $4 \mathrm{~cm}$, AC-BC setebal $6 \mathrm{~cm}$ dan Lapis Pondasi Atas (LPA) setebal $40 \mathrm{~cm}$ dengan besar perkiraan Rencana Anggaran Biaya pembangunan perkerasan lentur ruas Tambelangan-Durjan Kabupaten Sampang sepanjang 1,145 km sebesar Rp 5.744.585.463,00.
\end{abstract}

Kata Kunci : $\quad$ Perkerasan Lentur, Pelebaran, Biaya, Transportasi 


\section{PENDAHULUAN}

Pada ruas jalan Tambelangan-Durjan merupakan salah satu ruas jalan lokal penghubung kecamatan Tambelangan dan kabupaten Bangkalan yang dilalui pengendara roda 4, roda 2 bahkan truk.Di ruas jalan Tambelangan-Durjan terdapat tempat penumbukan bongkahan pasir urug sehingga banyak truk melewati ruas jalan tersebut. Truk tersebut mengangkut hasil bongkahan pasir urug dari luar daerah untuk ditumbuk menjadi halus dan didistribusikan ke daerah lain.Berdasarkan fungsinya ruas jalan Tambelangan-Durjan merupakan jalan lokal, berdasarkan statusnya ruas jalan Tambelangan-Durjan adalah jalan kabupaten sedangkan berdasarkan kelasnya ruas jalan Tambelangan-Durjan adalah jalan kelas III. Dari tahun ke tahun kondisi eksisting perkerasan jalan pada ruas jalan ini sangat memprihatinkansehingga membuat para pengendara dan masyarakat disekitar merasa resah.Terlebih saat musim hujan melihat kondisi jalan sudah tidak layak dilalui sehingga sering terjadi kecelakaan. Selain itu lebar jalan di ruas jalan Tambelangan-Durjan tidak sesuai dengan persyaratan teknis jalan dan kriteria perencanaan teknis jalan Peraturan Pemerintah No.19/PRT/M/2011 dengan jalan lokal kelas III lebar jalur lalu lintas $2 \times 2,75 \mathrm{~m} \mathrm{[1][2][3].Sehubungan} \mathrm{dengan} \mathrm{uraian} \mathrm{diatas} \mathrm{maka} \mathrm{diperlukan} \mathrm{merencanakan}$ perencanaan perkerasan lentur pada ruas jalan Tambelangan-Durjan Kabupaten Sampang mengingat ruas jalan tersebut jalan lokal penghubung kecamatan dengan kabupaten [4][5][6]. Dalam studi perencanaan ini akan dilakukan perencanaan ulang tebal lapis dan lebar perkerasan lentur menggunakan Metode Manual Desain Perkerasan 2017.

\section{METODE PENELITIAN}

\subsection{Lokasi Penelitian.}

Penelitian ini dilakukan di proyek Jalan Ruas Jalan Tambelangan - Durjan Kabupaten Sampang.

\subsection{Kepustakaan}

Studi terdahulu ini menjadi salah satu acuan yang digunakan dalam melakukan penelitian sehingga dapat memperkaya teori yang digunakan dalam mengkaji penelitian yang dilakukan. Dilihat dari studi terdahulu tidak adanya kesamaan judul dengan judul penelitian yang akan dilakukan. Namun penulis mengangkat beberapa penelitian sebagai referensi dalam memperkaya bahan kajian. Berikut merupakan penelitian terdahulu berupa beberapa jurnal terkait yaitu studi terdahulu yang berjudul “ Bidding Risk Factor Analysis Below Estimates on Quality Performance of Building Construction Projects in East Java Trenggalek City [7][8][9] dan Optimalisasi Tebal Perkerasan Pada Pekerjaan Pelebaran Jalan dengan Metode MDPJ 02/M/BM/2013 dan Pt T-012002-B. Universitas Lampung. 2016 [10][11][12] dan dari analisis yang telah dilakukan, dapat 
diketahui desain dengan biaya konstruksi awal terendah yaitu perkerasan dengan metode Bina Marga Pt-T-01-2002-B, sedangkan desain dengan biaya siklus hidup terendah adalah perkerasan dengan metode MDPJ 02/M/BM/2013 yang merupakan tebal perkerasan yang paling optimal.Sedangkan hasil analisa biaya pada perkerasan kaku untuk panjang jalan $8000 \mathrm{~m}$ dan lebar jalan 7.00 m sebesar RP. 44.412.355.000,00 dan Optimalisasi Tebal Perkerasan Pada Pekerjaan Pelebaran Jalan Dengan Metode MDPJ 02/M/BM/2013 dan PT T-01-2002-B pada Ruas Jalan Metro - Gedung Dalam Lampung.

\subsubsection{Lapis Perkerasan Lentur}

“ Konstruksi perkerasan lentur terdiri dari lapisan-lapisan yang diletakkan di atas tanah dasar yang telah dipadatkan.Lapisan-lapisan terseut berfungsi untuk menerima beban lalu lintas dan menyebarkannya ke lapisan di bawahnya "[13] [14][15].

"Konstruksi perkerasan terdiri dari :

1. Lapisan permukaan (surface course)

2. Lapisan pondasi atas (base course)

3. Lapisan pondasi bawah (subbase course)

4. Lapisan tanah dasar (subgrade) "[16]

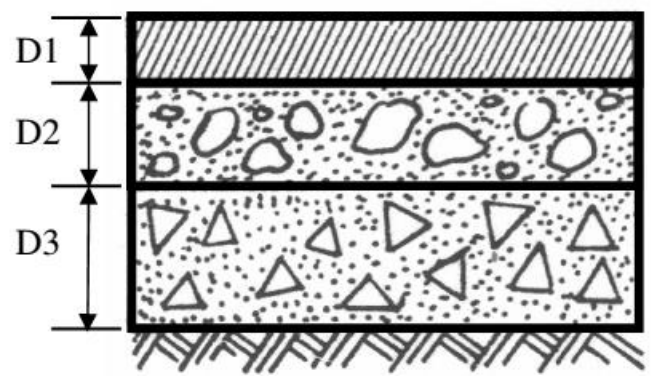

Gambar 1. Susunan Lapis Perkerasan Jalan

Sumber : SKBI 2.3 26.1987./UDC 625.73(02)

Beban lalu lintas yang bekerja di atas konstruksi perkerasan dapat dibedakan atas :

1. Muatan kendaraan berupa gaya vertikal

2. Gaya rem kendaraan berupa gaya horizontal

3. Pukulan roda kendaraan berupa getaran-getaran.

“ Karena sifat penyebaran gaya maka muatan yang diterima oleh masing-masing lapisan berbeda dan semakin kebawah semakin kecil. Lapisan permukaan harus mampu menerima seluruh jenis gaya yang bekerja, lapis pondasi atas menerima gaya vertikal dan getaran, sedangkan tanah dasar dianggap hanya menerima gaya vertikal saja. Oleh karena itu, terdapat perbedaan syaratsyarat yang harus dipenuhi oleh masing-masing lapisan" [17] [18]. 


\subsubsection{Rencana Anggaran Biaya}

“ Rencana Anggaran Biaya suatu proyek adalah perhitungan banyaknya biaya yang diperlukan untuk bahan dan upah tenaga kerja bedasarkan analisis serta biaya-biaya lain yang berhubungan dengan pelaksanaan proyek [19].Rencana Anggaran Biaya merupakan jumlah dari masing-masing hasil perkalian volume dengan harga Satuan pekerjaan yang bersangkutan ". [20] [21] [22].

Secara Umum dapat disimpulkan sebagai berikut :

$\mathrm{RAB}=\sum$ (Volume $\mathrm{x}$ Harga Satuan Pekerjaan)

Dalam menyusun anggaran biaya dibutuhkan data volume pekerjaan dan harga satuan perkerjaan.

\subsection{Runtutan Studi}

\subsubsection{Metode Pengumpulan Data}

"Setiap perencanaan akan membutuhkan data untuk meyelesaikan perencanaan yang akan dilakukan. Perencanaan juga membutuhkan data-data pendukung yaitu data peimer dan data sekunder.Data-data yang digunakan dalam studi perencanaan ini adalah data sekunder ". Data sekunder adalah data kearsipan yang dapat diperoleh dari perusahaan atau badan tertentu dan pihak instan terkait

\subsubsection{Metode Analisa Studi}

\subsubsection{Kriteria Perencanaan}

Kriteria Perencanaan Ruas Jalan Tambelangan-Durjan Kabupaten Sampang merupakan jalan lokal dan direncanakan jumlah jalur sebanyak satu lajur.

\subsubsection{Metode Analisa Studi}

Metode analisa studi akan menjelaskan langkah-langkah dalam perencanaan perkerasan lentur. Langkah-langkah yang dilakukan adalah sebagai berikut :

1. Pengumpulan data-data yang diperlukan dalam perencanaan perkerasan lentur yaitu data LHR, Data pertumbuhan Lalu lintas, Data CBR dan lain lain.

2. Penetapan Kriteria Jalan

Dalam menetapkan Kriteria Teknis Jalan mengacu pada Peraturan Mentri Pekerjaan Umum No. 19/PRT/M/2011 tentang persyaratan teknis jalan dan kriteria perencanaan teknis jalan.

3. Menentukan tipe perkerasan dari tabel atau dari pertimbangan biaya (analisis discounted whole of life cost)

4. Menentukan struktur perkerasan yang memenuhi syarat.

5. Menggambar tebal lapisan perkerasan lentur hasil desain. 
6. Perhitungan Rencana Anggaran Biaya

Perhitungan Rencana Anggaran Biaya ini termasuk menentukan volume pekerjaan perkerasan lentur, analisa biaya dan rekapitulasi RAB yang mengacu kepada Peraturan Mentri Pekerjaan Umum dan Perumahan Rakyat Republik Indonesia No. 28/PRT/M/2016 tentang Pedoman Analisis Harga Satuan Pekerjaan Bidang Pekerjaan Umum.

\section{HASIL DAN PEMBAHASAN}

3.1 Menentukan tipe perkerasan dari tabel atau dari pertimbangan biaya (analisis discounted whole of life cost)

Untuk menentukan tipe perkerasan (analisis discounted whole of life cost) Pemilihan Jenis Perkerasan dilihat dari perhitungan yaitu

- Umur rencana $=10$ tahun

$-\mathrm{CESA}_{4} \quad=467201,314$

Jadi ESA dalam 10 tahun pangkat 4 diantara 0,1-4 juta ESA ${ }^{4}$ dan menggunakan jenis perkerasan AC atau HRS tipis diatas lapis fondasi berbutir menggunakan bagan desain 3A (ESA pangkat4) seperti tabel dibawah ini :

Tabel 1. Pemilihan Jenis Perkerasan

\begin{tabular}{|c|c|c|c|c|c|c|}
\hline \multirow{3}{*}{ Struktur Perkerasan } & \multirow{3}{*}{$\begin{array}{l}\text { Bagan } \\
\text { desain }\end{array}$} & \multicolumn{5}{|c|}{ ESA (juta) dalam Stahun } \\
\hline & & & jangkat & Egecuali d & tentukan & in) \\
\hline & & $0-0,5$ & $0,1-4$ & $=14-10$ & $>10-30$ & $>30-200$ \\
\hline $\begin{array}{l}\text { Perkerasan lcaku dengan lalu lintas } \\
\text { berat (diatas tanah dengan } C B R \geq \\
2,5 \% \text { ) }\end{array}$ & 4 & - & - & 2 & 2 & 2 \\
\hline $\begin{array}{l}\text { Perkerasan lcaku dengan lalu lintas } \\
\text { rendah (daerah pedesaandan } \\
\text { perkotaan) }\end{array}$ & $4 \mathrm{~A}$ & - & 1,2 & - & - & - \\
\hline $\begin{array}{l}\text { ACWC modifikasi atau SMLA } \\
\text { modifikasi dengan CTB } \\
\text { pangkat5) }\end{array}$ & 3 & - & - & - & 2 & 2 \\
\hline AC dengan CTB (ESA pangkat5) & 3 & - & - & - & 2 & 2 \\
\hline $\begin{array}{l}\text { AC tebal } \geq 100 \mathrm{~mm} \text { dengan lapis } \\
\text { fondasi berbutir (ESA pangkat5) }\end{array}$ & $3 B$ & - & - & 1,2 & $\begin{array}{c}2 \\
----\end{array}$ & 2 \\
\hline $\begin{array}{l}\text { AC atau HRS tipis diatas lapis } \\
\text { fondasi berbutir }\end{array}$ & 3A & - & 1,2 & - & - & L \\
\hline 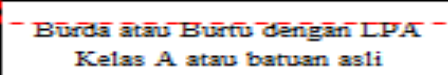 & $-\frac{1}{5}$ & $-\frac{-1}{3}$ & 3 & - & ---- & $\begin{array}{r}-1 \\
--1\end{array}$ \\
\hline Lapis Fondasi Soil Cement & 6 & 1 & 1 & - & - & - \\
\hline $\begin{array}{l}\text { Perkerasan tanpa penutup (Japat, } \\
\text { jalan keriki1) }\end{array}$ & 7 & 1 & - & - & - & - \\
\hline
\end{tabular}

Sumber : Bina Marga MDPJ No. 04/SE/Db/2017, 2017

\subsection{Menentukan Struktur perkerasan}

Dari pemilihan perkerasan diatas diadapatkan AC atau HRS tipis diatas lapis fondasi 
berbutir maka dipilih tabel 2. Bagan Desain - 3A Desain Perkerasan Lentur - aspal dengan Lapis Pondasi Berbutir.

Tabel 2. Bagan Desain

\begin{tabular}{|c|c|c|c|c|c|c|c|c|c|}
\hline & \multicolumn{9}{|c|}{ STRUKTUR PERKERASAN } \\
\hline & FFF1 & FFF2 & FFF3 & FFF4 & FFF5 & FFF6 & FFF7 & FFF8 & FFF9 \\
\hline \multicolumn{5}{|c|}{$\begin{array}{c}\text { Solusi yang } \\
\text { dipilih }\end{array}$} & \multicolumn{5}{|c|}{$\begin{array}{c}\text { Lihat } \\
\text { Catatan2 }\end{array}$} \\
\hline $\begin{array}{c}\text { Kumulatif beba nsumbu } 20 \\
\text { tahun pada lajur } \\
\text { rencana( }\left(10^{6} \mathrm{ESA} 5\right)\end{array}$ & $<2$ & $\geq 2-4$ & $>4-7$ & $>7-10$ & $>10-20$ & $>20-30$ & $>30-50$ & $>50-100$ & $>100-200$ \\
\hline \multicolumn{10}{|c|}{ KETEBALAN LAPIS PERKERASAN (mm) } \\
\hline ACWC & 40 & 40 & 40 & 40 & 40 & 40 & 40 & 40 & 40 \\
\hline $\mathrm{AC} B C$ & 60 & 60 & 60 & 60 & 60 & 60 & 60 & 60 & 60 \\
\hline AC Base & 0 & 70 & 80 & 105 & 145 & 160 & 180 & 210 & 245 \\
\hline LPAKelas A & 400 & 300 & 300 & 300 & 300 & 300 & 300 & 300 & 300 \\
\hline Catatan & \multicolumn{2}{|c|}{1} & \multicolumn{2}{|c|}{2} & \multicolumn{5}{|c|}{3} \\
\hline
\end{tabular}

Sumber : Bina Marga MDPJ No. 04/SE/Db/2017, 2017

Dalam tabel diatas didapatkan tebal lapisan struktur perkerasan dari perhitungan $\mathrm{CESA}_{5}$ yaitu :

$$
\begin{array}{ll}
- & \text { Umur rencana }=10 \text { tahun } \\
- & \mathrm{CESA}_{5} \quad=887682,4971 \\
\text { - } & \mathrm{CBR}_{\text {segmen }} \text { rencana }=5,499 \%
\end{array}
$$

Pada tabel yang memenuhi tabel kumulatif beban sumbu 10 tahun pada lajur kurang dari $0,5 \times 10^{6}\left(<0,5\left(10^{6} \mathrm{ESA}_{5}\right)\right)$. Tetapi pada Bagan desain 3B terdapat catatan bahwa penggunaan Bagan Desain 3B harus lebih diutamakan daripada Bagan Desain 3A pada tabel 2, maka ketebalan lapis perkerasan yang didapatkan adalah

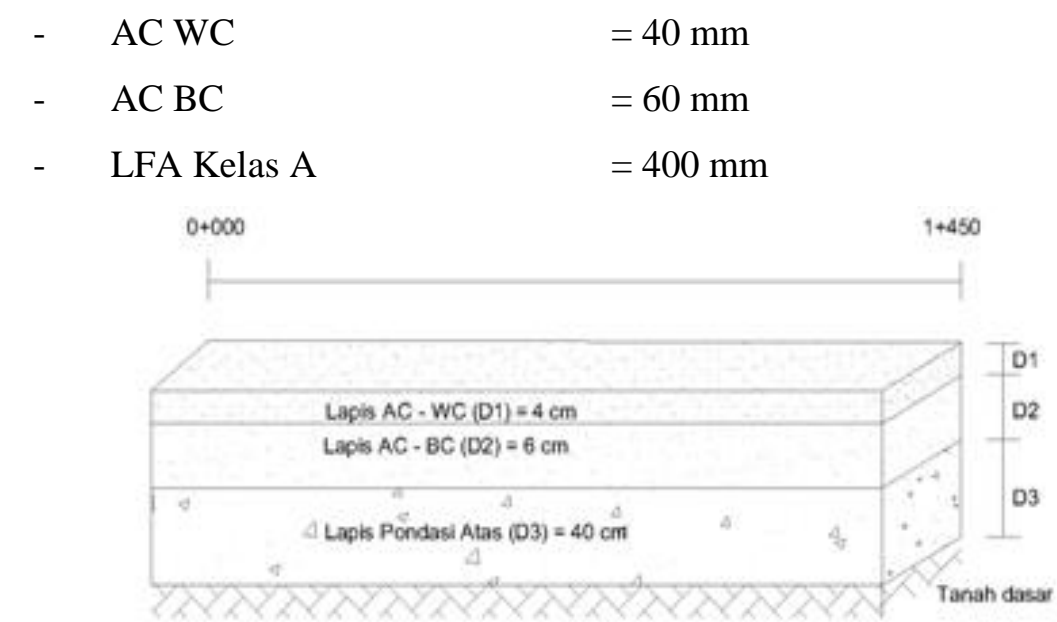

Sumber : Bina Marga MDPJ No. 04/SE/Db/2017, 2017 
Gambar 2 Penampang Tebal Lapis Perkerasan

\subsection{Perhitungan Rencana Anggaran Biaya}

Perhitungan Rencana Anggaran Biaya akan dihitung berdasarkan tebal perkerasan lentur yang telah dihitung. Lebar jalan 5,5 meter dan total panjang jalan 1,145 meter.

Dengan ketebalan setiap lapisannya sebagai berikut :

$\begin{array}{lll}- & \text { AC WC } & =40 \mathrm{~mm} \\ - & \text { AC BC } & =60 \mathrm{~mm} \\ - & \text { LFA Kelas A } & =400 \mathrm{~mm}\end{array}$

Semua rangkaian pekerjaan di analisa berdasarkan Analisa Harga Satuan Pekerjaan (AHSP) tahun 2019 dan Harga Satuan Pokok Kegiatan (HSPK) Pemerintah Kabupaten Sampang tahun 2019 yang diperoleh dari Kantor Dinas Pekerjaan Umum Bina Marga Kabupaten Sampang.

Data-data ini digunakan untuk menghitung analisa satuan harga sehingga didapatkan Rencana Anggaran Biaya (RAB) untuk perkerasan lentur Ruas Jalan Tambelangan-Durjan Kabupaten Sampang.

Tabel 3. Informasi Kegiatan Pekerjaan

\begin{tabular}{|r|l|l|}
\hline No & \multicolumn{1}{|c|}{ URAIAN } & \multicolumn{1}{|c|}{ INFORMASI } \\
\hline 1 & Lokasi pekerjaan & Jalan Tambelangan-Durjan \\
2 & Kondisijalan lama & Rusak, berlubang \\
3 & Panjang efektif (lihat sketsa dibawah) & 1,145 kilometer \\
& Lebar jalan lama (bahu + perkerasan + & $(0,50+2,00+0,50)$ meter \\
4 & perkerasan) & $(1,00+5,50+1,00)$ meter \\
5 & Lebar rencana (bahu + perkerasan + bahu) & 360 hari kalender \\
6 & Jarak waktu pelaksanaan pekerjaan & L \\
7 & Jarak rata-rata Base Camp ke lokasi pekerjaan & $=3,73$ kilometer \\
\hline
\end{tabular}

Sumber : Bina Marga MDPJ No. 04/SE/Db/2017, 2017

\subsubsection{Rekapitulasi Biaya}

Rencana Anggaran Biaya Perkerasan Lentur Ruas Tambelangan-Durjan Kabupaten Sampang. Berikut tabel Rencana Anggaran Biaya :

Tabel 4. Rencana Anggaran Biaya Perkerasan Lentur Ruas Tambelangan-Durjan Kabupaten Sampang.

\begin{tabular}{|c|c|c|c|c|c|}
\hline NO & Uraian Pekerjaan & satuan & volume & $\begin{array}{c}\text { Harga Satuan } \\
(\mathrm{Rp})\end{array}$ & Harga Pekerjaan (Rp) \\
\hline $\mathrm{a}$ & $\mathrm{b}$ & $\mathrm{c}$ & $\mathrm{d}$ & $\mathrm{e}$ & $\mathrm{f}$ \\
\hline 1 & Pekerjaan Persiapan & & & & \\
\cline { 2 - 6 } & Pembongkaran Jalan Lama & $\mathrm{m}^{3}$ & 2290 & 271.505 & 621.745 .593 \\
\hline
\end{tabular}




\begin{tabular}{|c|c|c|c|c|c|}
\hline \multirow[t]{2}{*}{2} & Pekerjaan Pekerasan & & & & \\
\hline & Lapisan Pondasi Atas & $\mathrm{m}^{3}$ & 1.145 & 869.357 & 995.414 .054 \\
\hline \multirow[t]{5}{*}{3} & Lapis Permukaan & & & & \\
\hline & Lapis Pengikat & liter & 5038 & 218.373 & 1.100 .164 .657 \\
\hline & Lapis Perekat & liter & 2519 & 216.621. & 545.668 .041 \\
\hline & Lapis Lastron AC-WC & ton & 591,965 & 704.544 & 417.065 .680 \\
\hline & Lapis Lastron AC-BC & ton & 884,169 & 761.107 & 672.946 .925 \\
\hline \multirow[t]{5}{*}{4} & Perkerjaan Bahu jalan & & & & \\
\hline & Bahu Jalan & $\mathrm{m}^{3}$ & 916 & 411.003 & 376.478 .604 \\
\hline & & & & & 4.729 .483 .553 \\
\hline & PPN & & & & $472.948 .355,55$ \\
\hline & & & & & 5.202.431.909 \\
\hline
\end{tabular}

Sumber : Analisa Perhitungan

\section{KESIMPULAN}

Hasil analisis perencanaan perkerasan lentur dan Renacan Anggaran Biaya ruas jalan Tambelangan-Durjan STA 0+000 - STA 1+145 Kabupaten Sampang Jawa Timur sebagai berikut

1. Tebal perkerasan lentur dengan lebar jalan 5,5 meter sebagai berikut :
Lapis Aus (AC WC)
$=4 \mathrm{~cm}$
Lapis pengikat (AC BC)
$=6 \mathrm{~cm}$
Lapisan Pondasi Atas (Subgrade) Kelas A
$=40 \mathrm{~cm}$

2. Jadi lebar tambahan yang perlu direncanakan adalah 2 meter, atau dilebarkan 1 meter pada setiap lajurnya.

3. Besar perkiraanRencana Anggaran Biayapembangunan perkerasan lentur Rp 5.202.431.909 termasuk PPN 10\%.

\section{SARAN}

Adapun saran yang penulis berikan dalam skripsi ini adalah sebagai berikut : Dalam menentukan tebal permukaan lapisan aspal sebaiknya menggunakan ketebalan yang sama, agar mempermudah pelaksanaan di lapangan. Apabila hasil perhitungan didapatkan hasil dengan bilangan pecah atau decimal sebaiknya dibulatkan saja, Saran untuk mahasiswa yang akan mengambil skripsi dengan tema perencaan perkerasan lentur dengan metode bina marga, dalam proses pengumpulan data sebaiknya harus lengkap dan mencari sumber data yang akurat yang mempermudah dalam pengambilan data. Untuk data DCP jarak titik pengamatan minimal 25 50 meter dan lebih baik menguji DCP sendiri. 


\section{UCAPAN TERIMAKASIH}

Dalam penyusunan artikel ini, penulis ucapkan terimakasih kepada dosen pembimbing dan Universitas Kadiri. Penulis berharap agar artikel ini dapat bermanfaat bagi pembaca.

\section{DAFTAR PUSTAKA}

[1] M. D. Agusti, E. Rita, and I. Khaidir, "Berat Pada Proyek Peningkatan Pembangunan Jalan Penggambiran Rura - Pratotang Kabupaten Pasaman Barat,” pp. 1-18, 2012.

[2] E. Kusnandar, "Manual Kapasitas Jalan Indonesia 1997,” J. Jalan dan Jemb., vol. 26, no. 2, pp. 1-11, 2009.

[3] A. I. Candra, A. Yusuf, and A. R. F, "Studi Analisis Daya Dukung Pondasi Tiang Pada Pembangunan Gedung Lp3M Universitas Kadiri,” J. CIVILA, vol. 3, no. 2, p. 166, 2018, doi: $10.30736 /$ cvl.v3i2.259.

[4] A. Badrujaman, "Perencanaan Geometrik Jalan Dan Anggaran Biaya Ruas Jalan Cempaka - Wanaraja Kecamatan Garut Kota," J. Konstr., vol. 14, no. 1, pp. 25-34, 2016.

[5] O. Nurahmi and A. A. G. Kartika, "Perbandingan Konstruksi Perkerasan Lentur dan Perkerasan Kaku serta Analisis Ekonominya pada Proyek Pembangunan Jalan Lingkar Mojoagung," J. Tek. ITS, vol. 1, no. 1, pp. 63-68, 2012.

[6] M. L. Pangerapan, T. K. Sendow, and L. Elisabeth, "Studi Perbandingan Perencanaan Tebal Lapis Tambah (Overlay) Perkerasan Lentur Menurut Metode Pd t-05- 2005-b dan Manual Desain Perkerasan Jalan 2013 (Studi Kasus : Ruas Jalan Bts . Kota Manado Tomohon)," J. Sipil Statik, vol. 6, no. 10, pp. 823-834, 2018.

[7] R. Ajiono, "Bidding Risk Factor Analysis Below Estimates on Quality Performance of Building Construction Projects in East Java Trenggalek City,” pp. 70-78, 1998.

[8] E. Gardjito, "STUDY PERENCANAAN GEOMETRIK, PERKERASAN JALAN DAN PERENCANAAN ANGGARAN BIAYA PADA JALAN RAYA KALIDAWIR - Ds. NGUBALAN Kec. KALIDAWIR,” UKaRsT, vol. 1, no. 2, pp. 94-101, 2017, doi: 10.30737/ukarst.v1i2.264.

[9] R. Hidayah, A. Ridwan, and Y. C. S. P, "ANALISA PERBANDINGAN MANAJEMEN WAKTU ANTARA PERENCANAAN DAN PELAKSANAAN," Jurmateks, vol. 1, no. 2, pp. 281-290, 2018.

[10] A. Andriansyah, P. Pratomo, and H. Ali, "Optimalisasi Tebal Perkerasan Pada Pekerjaan Pelebaran Jalan dengan Metode MDPJ 02/M/BM/2013 dan Pt T-01-2002-B,” J. Rekayasa Sipil dan Desain, vol. 4, no. 1, pp. 113-126, 2016.

[11] A. Susanto, Y. C. S. P, and S. Winarto, "STUDI PERENCANAAN JEMBATAN CUMPLENG DENGAN METODE PRATEKAN DI KEC. SLAHUNG KABUPATEN 
PONOROGO,” Jurmateks, vol. 1, no. 2, pp. 172-181, 2018.

[12] H. Prasetiawan, A. Ridwan, and Y. C. S. P, "EVALUASI PENGENDALIAN MUTU PADA PROYEK PEMBANGUNAN OBYEK WISATA SEDUDO DI KABUPATEN NGANJUK,” Jurmateks, vol. 2, no. 1, pp. 65-74, 2019.

[13] A. D. Limantara, S. Winarto, and S. W. Mudjanarko, "SISTEM PAKAR PEMILIHAN MODEL PERBAIKAN PERKERASAN LENTURBERDASARKAN INDEKS KONDISI PERKERASAN ( PCI )," no. November, pp. 1-2, 2017.

[14] [Kementerian PUPR]. Kementerian Pekerjaan Umum dan Perumahan Rakyat direktorat jendral bina marga and D. J. B. Marga, "Manual Desain Perkerasan Jalan," Nomor 02/M/BM/2013, 2013.

[15] A. Kholiq, "Perencanaan Tebal Perkerasan Lentur Jalan Raya Antara Bina Marga Dan Aashto'93 (Studi Kasus: Jalan Lingkar Utara Panyingkiran-Baribis Ajalengka),” JEnsitec, vol. 1, no. 01, pp. 43-51, 2014, doi: 10.31949/j-ensitec.v1i01.15.

[16] A. D. Limantara, A. I. Candra, and S. W. Mudjanarko, "MANAJEMEN DATA LALU LINTAS KENDARAAN BERBASIS SISTEM INTERNET CERDAS KADIRI," semnastek, no. November, pp. 1-2, 2017.

[17] D. J. B. Marga, "Departemen Pekerjaan Umum," Man. Kapasitas Jalan Indones. (MKJI 1997), Jakarta, 1997.

[18] S. Sukarman, Beton Aspal Campuran Panas. Yayasan Obor Indonesia, 2003.

[19] H. R. Agustapraja and Affandi, "PERBANDINGAN ESTIMASI ANGGARAN BIAYA DENGAN METODE SNI DAN BOW PADA PROYEK PEMBANGUNAN GEDUNG D FAKULTAS AGAMA ISLAM UNIVERSITAS ISLAM LAMONGAN," Ukarst $J$. Univ. Kadiri Ris. Tek. Sipil, vol. 1, no. 2, pp. 84-93, 2017.

[20] I. Bachtiar, "Rencana dan estimate Real of Cost," Jakarta Bumi Aksara, 1993.

[21] E. Gardjito, "STUDY PERENCANAAN GEOMETRIK, PERKERASAN JALAN DAN PERENCANAAN ANGGARAN BIAYA PADA JALAN RAYA KALIDAWIR-Ds. NGUBALAN Kec. KALIDAWIR,” UKaRsT, vol. 1, no. 2, p. 11, 2017.

[22] A. C. Mujianto, L. C. A. R. Jonathan, and A. Suroso, "EFISIENSI BIAYA PEMBANGUNAN PROYEK JALAN SP RESAK PETUNG PADA PT BANGUN CIPTA KONTRAKTOR,” EKONOMIA, vol. 5, no. 1, pp. 68-73, 2016. 